\title{
Research on the Construction of Sustainable Competitive Advantage of Start-up Enterprises Based on Dynamic Capability
}

\author{
Yan $\mathrm{CHEN}^{\mathrm{a}}$, Xiao-Ling WANG ${ }^{\mathrm{b},{ }^{*}}$ and Bo YANG $^{\mathrm{c}}$ \\ Jiangxi Normal University, No.99 Ziyang Road, Nanchang, Jiangxi, China \\ achenyan95404@163.com, bxiaoling6302@sina.com, ncby@qq.com \\ ${ }^{*}$ Corresponding author
}

Keywords: Dynamic capability, Entrepreneurial enterprise, Sustainable competitive advantage.

\begin{abstract}
With the increasing sophistication of information technology and the " Internet + Strategy " advocated by the government, traditional industry entrepreneurs are facing increasing competition pressure. How to cultivate its dynamic ability to maintain sustainable competitive advantage becomes an urgent task. In this paper, the relevant research theories about dynamic capability and sustainable competitive advantage at home and abroad are roughly sorted, this paper analyzes the mechanism of dynamic capability to construct sustainable competitive advantage of start-up enterprises, and finds that the construction of sustainable competitive advantage is a process that relies on enterprise dynamic capability to continuously carry out resource reorganization and continuous innovation. On this basis, the author puts forward some suggestions on how to use dynamic capability to build sustainable competitive advantage.
\end{abstract}

\section{Introduction}

Traditional retail enterprises have been confronted with the problems of high cost, high competition, low return and difficult expansion from the beginning of the year. With profit margins and declining performance, the cost of operating a physical store is getting higher. While the internet economy is becoming more developed and the overall economic growth of the country slows down, physical retailing is worse, facing a severe challenge of low performance and negative profits. 2015 The first half of the year has seen a wave of " closures "in the traditional retail industry. Although the physical retail and electric dealers seem to be incompatible with each other, and the public opinion has been one-sided forecasts that the electricity will quickly replace the traditional retail, but a few years in the past, the rapid development of electronic business, physical retailing, although by no small impact, is still stubbornly upright. Although the development of E-commerce has brought a certain impact on the retail industry, but its development also has a lot of positive significance, because it to the traditional retail industry has brought unprecedented changes, forcing the whole entity business from the mode to the service and other details from the table to improve. In the face of severe survival pressure, the traditional retail industry began to rethink, how real business combined with the reality to make effective innovation? How to create a sustainable competitive advantage in this wave of Internet?

\section{Literature Review}

\section{Overview of Dynamic Capabilities Research}

The theoretical origins of dynamic capability can be traced back to the theory of evolutionary economics explaining the evolution of organization. At present, the dynamic capability integrates the former structural knowledge, organizational inertia, unique competitiveness, core competitiveness and other theoretical viewpoints. It compensates for the previous theory from a single point of view of enterprise capacity in the internal or external deficiencies. Scholars such as Teece have attracted the interest of many scholars after the concept of dynamic capability was presented in 1997 year. The academic circles have deeply studied the intension characteristic, the 
factor structure, the function mechanism, the influence factor and the practical application of dynamic ability. Scholars have made different definitions of the concept and dimension of dynamic ability from different viewpoints.

Teece considered that Dynamic capability is the ability of an enterprise to consolidate, build, and restructure internal and external resources and competitiveness in response to rapidly changing external environments. Thus, he presented the 3P framework "position, process and path". It is considered as an important source of sustainable competitive advantage. However, many scholars have questioned about this. Eisenhardt and Martin from the perspective of the narrow dynamic capability structure dimension, the paper points out that enterprise dynamic capability is an identifiable conventional strategic practice and organization process, which can make the enterprise more rapid, sharp, flexible to adapt to the requirements of internal and external environmental changes, it includes the integration, update, reorganization of resources and the release of a series of actions. At the same time, scholars also studied the dimensions of dynamic capability. Wang and Ahmed Also consider that the dynamic capability of an enterprise is a class concept, and based on this, the three dimensions of dynamic capability are proposed. adaptability, Ability to absorb and innovate. In recent years, domestic scholars have also put forward their own views on dynamic capability dimensions, Feng Military and military and Wei jiang According to the analysis of the foreign dynamic capability dimension, dynamic capability includes the perception of opportunity and threat, the ability of resource integration and the ability of resource reconstruction. On the basis of previous research, Dong Baobao divided the dynamic capability into environmental adaptability, organizational change ability, resource integration ability, learning ability and strategic isolation mechanism.

Based on the above analysis, this paper holds that the dynamic capability table of start-up enterprises can now identify the dynamic environment faced by enterprises, take internal and external learning activities, quickly absorb and combine the actual innovation of the company. The dynamic capability of an enterprise can be divided into three dimensions: perceptual ability, integration ability and innovation ability.

\section{Overview of Sustainable Competitive Advantage Research}

Selznick first presented a detailed concept of competitive advantage in 1957, he said Competitive advantage is that the enterprise in the market competition in the process of exceeding or surpassing other competitors and can create excess profits within a certain period or gain higher than the average profit level of the industry attributes or ability. You Daming, Peng wei said Sustainable competitive advantage has two rendering. First, a certain point of the competitive advantage in the long period of continuation and maintenance, the second is a continuous superposition of several short advantages. Based on this, the sustainable competitive advantage is defined as a balance of competitive advantage after all imitation attempts are imitated. Wu according to the research of High-tech start-ups, the enterprise's competitive advantage is defined as the ability of the enterprise's human capital which is higher than the competitor's efficiency in the market. Ma Hongjia, Dong Baobao considered that the competitive advantage of an enterprise is that an enterprise is superior to its competitors in its internal operating environment and external market environment, such as internal innovation speed, product quality, external market performance. The comprehensive and above analysis, this article believes that sustainable competitive advantage is an iterative process can not be accomplished overnight. Enterprises in the use of their own resources and ability to gain a competitive advantage, enterprises in the market competition will achieve a stable and balanced state. However, with the change of dynamic environment, this kind of equilibrium will be broken, and the enterprise must use dynamic capability to reorganize resources again in order to gain new competitive advantage.

\section{The Mechanism of Dynamic Capability to Build a Sustainable Competitive Advantage}

Since the age of Century, the dynamic capability Research has become the frontier subject of the current enterprise strategy research with the dynamic enhancement of the external environment. At 
the same time, in the face of the rapid development of the Internet to the commercial situation, the theorists pay more and more attention to the growth process of the new enterprise, dynamic ability of the entrepreneurial enterprise sustainable competitive advantage to cultivate a positive role has been confirmed. Nowadays, with the development of information technology, the scope of commercial trade has already crossed the limitation of time and space. Enterprises can not ignore the impact of dynamic environment on the development of enterprises. The lack of experience, capacity accumulation of new ventures, especially, enterprises must be more than competitors to provide customers with more valuable services or products, in order to gain sustainable competitive advantage in the market competition.

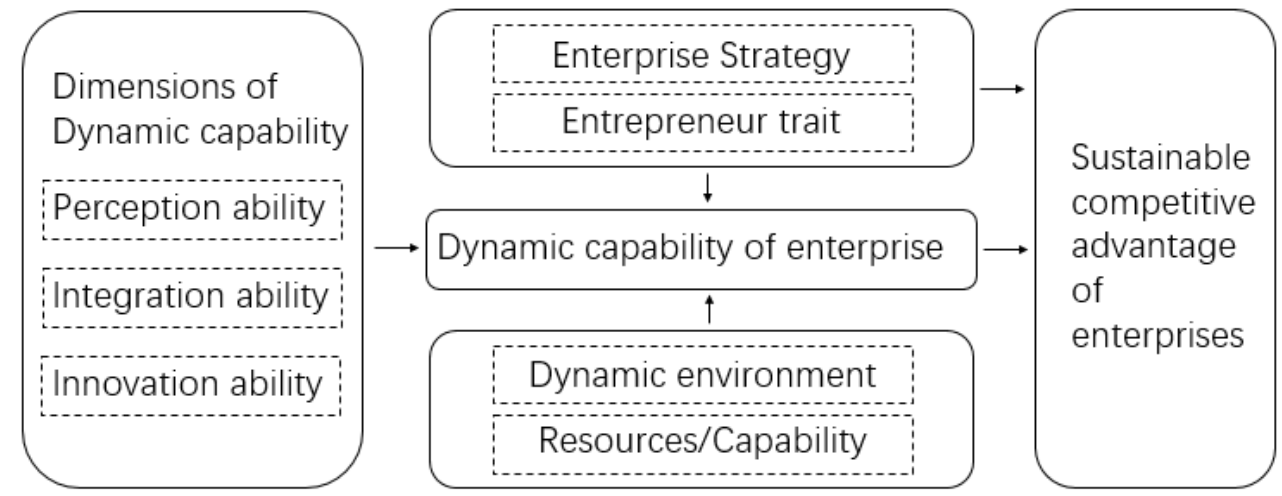

Fig. 1 The action mechanism of dynamic capability on competitive advantage of enterprises

The dynamic mechanism of the external market and the existing resources of the enterprise are the basic conditions for the start-up enterprises to form dynamic capability. Dynamic changing market is the forerunner of dynamic capability development, and the more environment uncertain factors, the stronger dynamic capability is required. The resources owned by enterprises are the foundation of their dynamic capability development, and the integration and utilization of resources is the strategy and skill for enterprises to achieve their goals.

The stronger the enterprise dynamic ability, the more the enterprise can form the unique ability. In the entrepreneurial period, enterprises are influenced not only by dynamic environment, but also by enterprise strategy and entrepreneur. In the entrepreneurial stage, the enterprise's purpose is to produce products or provide services in the market to survive, enterprises focus on how to meet customer needs. Entrepreneurs devote all their energy to production technology activities and marketing, focusing on the ability to improve productivity, the ability to integrate resources, and the ability to meet customer value propositions. Enterprises in the dynamic environment to better cater to consumers must be integrated and reconstructed their ability, which will form dynamic capacity. and the dynamic ability of the strength directly determines the evolution of enterprise capabilities. Because different enterprises have different emphases in different life cycle, the difference of strategy will also form the heterogeneity of development path. In addition, the ability of entrepreneurs can also affect the development of entrepreneurial capabilities, the ability of entrepreneurs to identify opportunities, change capabilities and the ability to foresee the future will affect the choice of enterprise capacity development.

If the strategic choice of enterprise matches with its capability development, dynamic ability has positive conduction effect on the formation of sustainable competitive advantage of the enterprise, and the conduction effect of dynamic capability will further improve the business performance. To study the ability of enterprises to obtain sustainable competitive advantage is the focus of dynamic capability theory. Dynamic capability has the characteristic of path dependence, which makes it more meaningful to study dynamic ability to develop sustainable competitive advantage. The perception ability, integration ability and innovation ability of enterprise in the start-up period play an important role in forming the sustainable competitive advantage of enterprises. 


\section{Dynamic Evolutionary Model of Sustainable Competitive Advantage}

To establish sustainable competitive advantage, enterprises must break through the complicated and changeable market predicament. After breaking through the existing predicament and establishing the competitive advantage, the enterprise will face the new market erosion with the change of time and space dimension. Therefore, across the time dimension, enterprises in the development process, we must repeatedly break the original competitive advantage, and constantly learn, adjust to build a new competitive advantage. This is the endogenous power of enterprise system evolution. Based on the cyclic process, the evolutionary model of sustainable competitive advantage is actually a spiral form.

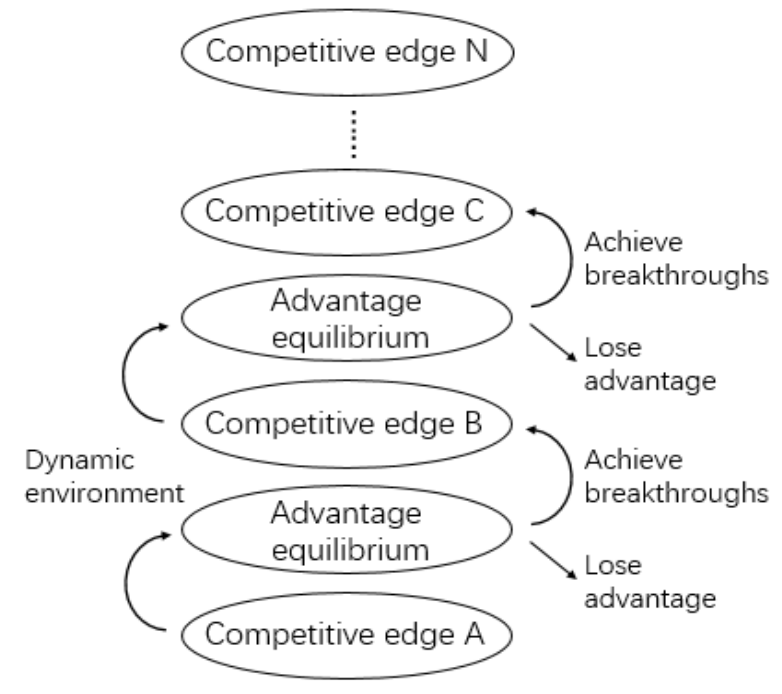

Fig.2 Dynamic Evolution Model of enterprise competitive advantage in dynamic environment

As the figure shows, competitive advantage is not immutable. Under the complicated changing market environment, the enterprise only has to break through the original management mode, make use of the existing resources and ability of the enterprise to carry on the continual adjustment, renew, realize the dialectic self-denial at a higher level or say discard, To achieve new breakthroughs, create new competitive advantages, beyond the market competitors. It is possible for enterprises to obtain sustainable competitive advantage and maintain a balanced state in the fierce market competition with this dynamic ability to adjust to dynamic environment changes. Therefore, enterprises must be good at identifying and grasping market opportunities, using existing resources to continuously break through the existing advantage equilibrium state, and build a series of new competitive advantages, thus forming the sustainable competitive advantage of enterprises.

\section{Conclusion and Revelation}

\section{Research Conclusions}

How to build a sustainable competitive advantage in a dynamic environment is explored from the perspective of dynamic capability. Enterprises in the entrepreneurial stage, because of the lack of management experience and control of scarce resources, often face a more severe living environment. At this stage, the purpose of the enterprise is to be able to produce products or provide services in the market to survive, and the focus of enterprise focus on whether to meet customer demand, open the market. Therefore, enterprises should not only have the common ability, but also to train the dynamic environment to reorganize the internal and external resources, so as to improve enterprise efficiency and the ability to obtain sustainable competitive advantage, that is, dynamic capability. The dynamic capability of entrepreneurial period has positive effect on the construction of sustainable competitive advantage. In addition, the paper holds that the construction process of sustainable competitive advantage of enterprises is not accomplished in a timely manner, enterprises need to recognize the change of dynamic environment in time, and continuously break 
through the existing market equilibrium state through resource reorganization to gain new competitive advantage.

\section{Revelation}

First, it is important to cultivate the dynamic capability of enterprises. Resources and ability are the foundation of dynamic capability construction, the lack of resources and ability of enterprises in entrepreneurial period may lead to the failure of entrepreneurial activities directly. Although entrepreneurial period enterprises often do not have a very complete resources and capacity, but must ensure that when faced with environmental change, enterprises have the ability to according to their own resources for strategic planning and adjustment. Therefore, enterprises in the start-up period should have as much basic resource base as possible, such as human resources, financial resources and technical resources. In the aspect of ability, we should focus on cultivating the learning ability, adaptability, absorptive ability and innovation ability of the enterprise.

Second, we should face the construction of sustainable competitive advantage. The construction of sustainable competitive advantage is not an overnight, but a repetitive, spiral process. The use of resources and capabilities may give the enterprise a temporary competitive advantage, but in the long run, dynamic capability is the long-term and direct impact on the enterprise's ability to build sustainable competitive advantage. Therefore, the new enterprise must pay attention to the development of dynamic ability to ensure the long-term growth of enterprises. The enterprise should continuously break through in the dynamic changing environment, so as to build a new competitive advantage continuously.

\section{Acknowledgement}

This research was supported by the project of National Natural Science Foundation of China (71662018) and was a phased achievement of "Microscopic Mechanism for the Formation of Dynamic Capabilities of Enterprises: From the Perspective of Innovative Flexible Human Resource Management".

This paper is also a milestone achievement of the Research on the Formation Mechanism of Dynamic Capabilities of Enterprises Based on Flexible Human Resource Management in Humanities and Social Sciences Research Project of Universities in Jiangxi Province (GL161002).

\section{References}

[1] Eisenhardt K, Martin J. Dynamic capabilities: what are they? [J]. Strategic Management Journal, 2000.

[2] Teece D J, Pisano G Schuen A. Dynamic capabilities and strategic management[J]. Strategic Management Journal, 1997.

[3] Wang C L, Ahmed P K. Dynamic capabilities: a review and research agenda[J]. International Journal of Management Reviews,2007.

[4] Wu L. Applicability of the resource-based and dynamic capability views under environmental volatility[J]. Journal of Business Research,2010.

[5] Cao Hongjun, Zhao Jianbo. How dynamic capabilities affect corporate performance - An Empirical Study Based on Chinese enterprises [J]. Nankai Management Review, 2008.

[6] Dong Baobao, Ge Baoshan, Wang Kan. Resource integration process, dynamic ability and competitive advantage: mechanism and path [J]. Management World, 2011.

[7] Jiao Hao, Wei Jiang, Cui Yu. Analysis of the dynamic capacity building path of enterprises: Based on the perspective of entrepreneurial orientation and organizational learning [J]. Management World, 2008. 
[8] Feng Junzheng, Wei Jiang. Review and Prospect of foreign dynamic capability dimension division and measurement research and Prospect [J]. Foreign Economy and Management, 2011.

[9] Lu Qian. The strategic choice of sustainable competitive advantage of enterprise dynamic environment technology [J]. Industrial Economy, 2004.

[10]Lin Ping. An exploration of the relationship between entrepreneurial ability and dynamic ability - an exploratory study based on multi case in-depth interview [J]. Journal of Shandong Institute of Business and Technology, 2012.

[11]Liu Jingjian. An Empirical Study on the relationship between dynamic ability and new enterprise performance [J]. China Science and Technology Forum, 2011.

[12] Ma Hongjia, Dong Baobao, Ge Baoshan. Research on the relationship between entrepreneurial ability, dynamic ability and competitive advantage of enterprise [J]. Science Research, 2014.

[13] Ma Weidong, Hu Changshen. Dynamic capabilities construction of business enterprise and its effect on the performance of [J]. Value Engineering, 2008.

[14] You Damien, Peng Wei, the establishment of strategic assets and sustainable competitive advantage [J]. Journal of Shijiazhuang University of Economics, 2004. 